\title{
"PATTERNS" OF THRESHOLD SPACES IN THE HISTORICAL CITY OF JEDDAH, SAUDI ARABIA
}

\author{
BASMA MASSOUD \\ Architectural Department, University of Sheffield, UK
}

\begin{abstract}
The availability of public space and its integration with private space is one of the important factors that is associated with the quality of urban settings. This paper aims to look at the ground floor in builtup areas from two different perspectives, public space and residential units. It mainly focuses on threshold spaces and investigates patterns between these two components while presenting a new way of approaching the Christopher Alexander theory and questions its impact on spatial and social levels. This paper will present an example of one pattern out of many identified patterns found in the historical city of Jeddah. The city of Jeddah was chosen as a case study for this research activity for several reasons. First, because of its role in Saudi society as it is the second largest city in Saudi Arabia after the capital (Riyadh). Second, because of the strong urban identity in the historical area. Third, the rapid growth in line with spatial planning, Last but not least, it represents a typical Islamic city where the findings can be relevant to other Islamic cities.
\end{abstract}

Keywords: public sphere, private sphere, notion of thresholds and patterns, Christopher Alexander theory, sustainable urban development, traditional urban planning.

\section{INTRODUCTION}

"The subdivision of spaces we inhabit into public and private spheres is a key feature in how a society organizes itself. It further affects the mental state, experience, regulates behaviour, and superimposes a long-lasting structure on to human society" [1, p. 1]. "The configuration of a city and the quality of urban life are largely influenced by the way the public and private distinction is made and how we transition between the two unique spaces, by creating a flexible and elaborated boundary between the two realms, urbanism can be enriched" [1, $p$. 121]. This transition space is usually referred to as a threshold that bridges the gap between the interior and the exterior and is formed when an urban transformation occurs. They usually vary in urban scale and help ease architectural relationships with the surrounding environment to reduce conflict.

This paper aims to examine the concept of "ground floor" and the continuation of the public and private spheres of the society and the relationship between the spheres through the threshold space. The meaning of the ground floor in this research is beyond the ground level of a building. It encompasses the surrounding open spaces and infrastructure [2], According to Zoller [2] "the ground floor largely defines how a city is perceived; it is the representative public face of the street, where buildings present themselves at eye level".

Furthermore, this paper will investigate certain patterns through an urban theory, which comes from Christopher Alexander "A pattern Language" within the threshold spaces in the old city of Jeddah that played a huge role in aiding the public life. In this paper patterns are referred to as anything that has a repeated effect on the context. According to Alexander et al. $[3$, p. x] each pattern describes a problem which occurs over and over again in our environment.

Jeddah's Historic centre, locally called Al Balad, is located at the heart of the city and has been a UNESCO world heritage site since 2014 [4] the old area includes a number of heritage buildings, transportation networks, and open spaces forming a homogenous pattern. 
Threshold spaces were embedded in areas of the urban fabric, linking the interior of private residential and public structures to the exterior public spaces.

It is important to highlight that customs "Urf" played an important role in shaping Islamic cities including Jeddah. In this paper Urf refers to local tradition rooted in people and becomes part of their being and culture that played an important role in establishing systems of rules to organize the street patterns and process in the old Islamic cities. "Urf can be found on the whole the smaller the scale the more evident the impact. Although in some instances we also find the effect on the larger scale" [5, p. 112].

Jeddah city is located along the west coast of the Red Sea in the western province of Saudi Arabia. It acts as a link between the Arabian Peninsula and Europe via the Suez Canal. Its importance lies in its location as it provides access to the holy city of Mecca for millions of Muslim pilgrims from all over the world.

The city of Jeddah was chosen as a case study for this research for several reasons; first, because of its role in Saudi society as it is the second largest city in Saudi Arabia after the capital (Riyadh). Second, because of the strong urban identity in the historical area. Third, the rapid growth in line with spatial planning, Last but not least it represents a typical Islamic city where the findings can be relevant to other Islamic cities.

There are countless methods for creating threshold spaces, this paper will give one example out of eighteen patterns found in the historical city of Jeddah. Moreover, it will explore the link between thresholds and social structure, and their impact on urban quality in the middle eastern city to understand how it played a role in enhancing the quality of life, something that has never been explored in detail, and constitutes a clear gap in the knowledge.

\section{METHODOLOGY}

This research is based on a methodological approach which is inspired by the theory of "A Pattern Language 1977" by Christopher Alexander. This paper aims to look at the concept of "ground floor" in built-up areas from two different perspectives, public space and residential units. The study focuses on the interface between these two components and questions its impact on spatial and social levels.

This qualitative research process which will be focusing on the architectural urban approach consists of several steps and is based on literature review, interviews, visual survey, intensive archive research which will be implemented through Jeddah Municipality to find data (document, maps, and images), personal observation, photography, drawing and analysing of existing situation of the threshold space.

The smaller the scale of pattern the more it is related and connected to human beings. On the other hand, the larger the scale pattern the harder it is for some people to understand its impact as it is not tangible. For this reason, this research is organized along five scales from the small to the largest, which form the bases of its investigations; Time, body, building, street, and city. Therefore, different methods are required for different scales.

- Time scale: deals with dynamic observation of spaces/sites in different times.

- Body scale: this closer humanized scale requires documenting lived experience through drawings, diagrams, observation, noting, detailed photographs and interviews. It is essential to work with this scale when investigating thresholds, as we can understand the elements and its relation to the body.

- Building scale: this close and more detailed scale requires diagrams, photography and drawings on multi layers. This scale plays an important role as we can understand for 
example the proximity between two buildings or the height of the window to the ground floor, etc.

- Street scale: this scale requires several approaches including archival, ethnographic methodologies, drawings, photography, etc., the importance of this scale lies in the fact of understanding several things such as the width of the street which allows neighbors contacts without visual connection.

- City scale: this scale requires archival research to understand the urban morphology, which will be implemented through Jeddah municipality to find data (maps, documents, and images). At this scale is it important to understand the relationship between the thresholds in the city, the proportions, typology, etc.

\section{PATTERNS AND CHRISTOPHER ALEXANDER THEORY}

Alexander and his colleges in a pattern language published 253 patterns after observing many medieval cities that they find attractive and harmonious. A pattern is a way of solving a problem that occurs several times in a context such as the need for Entrance Transition.

In his book he had a certain format for presenting his patterns. First, a picture of an archetypical example of the pattern. Second, statement that explains the context of the pattern and how this pattern can help in completing larger patterns. Third, a problem statement explaining the core problem. Fourth, the body paragraph made of research of the problem, its necessity and when possible showing different ways the pattern may occur. Fifth, a statement in the form of an instruction. Sixth, a solution in the form of a diagram. Last, a paragraph with a number of smaller patterns that helps completing this pattern. Moreover, patterns are organized according to scale from the largest to the smallest (town, building, construction). The larger pattern requires medium patterns and the medium patterns require smaller patterns to complete the larger ones. From that we can conclude that the patterns are not isolated but are reinforced by other patterns to help complete each other.

\subsection{How do patterns form a language?}

Alexander looks at the patterns as a language for designers and non-designers made by people in society as a way of expressing one's self in a space and making towns and buildings alive and liveable. "It is possible to make buildings by stringing together patterns, in a rather loose way. A building made like this is an assembly of patterns. It is not dense. It is not profound. But it is also possible to put patterns together in such a way that many, many patterns overlap in the same physical space: the building is very dense: it has many meanings captured in a small space; and through this density, it becomes profound" [3, p. x1i]. Upon that, each pattern is related to many other patterns and to the whole language. Meaning the relationship of patterns together forms the language that creates the living city.

\section{THRESHOLD SPACES}

Threshold space is a term that was used in different disciplines to describe different transitional conditions from various perspectives. Therefore, it has developed a countless number of different meanings. it is not restricted to the shell of the building with its openings from entrance and window, it is more than that. It connects the inside with the outside and it's a fundamental feature of any special arrangement in architectural. Below is a selection of these definitions.

In ethnography, Van Gennep [6] had one of the first studies on cultural rites, he describes the transitional moment in ritual where one state is left and other is entered. 
Turner [7] further propound that thresholds "are neither here nor there; they are betwixt and between the positions assigned and arrayed by law, custom, convention, and ceremonial".

Alexander et al. [3, p. 549] argues that "while people are on the street, they adapt a style of 'street behaviour'. When they come into a house they naturally want to get rid of this street behaviour and settle down completely into the more intimate spirit appropriate to a house. But it seems likely that they cannot do this unless there is a transition from one to the other which helps them to lose the street behaviour. The transition must, effect, destroy the momentum of the closedness, tension and 'distance' which are appropriate to street behaviour, before people can relax completely". Upon that, we understand the significance of creating an in between space to allow a graduate movement and change between two heterogeneous spheres with different qualities and characteristics and combining two different functions which allows the change of experience to take place in a gradual manner, such space is called threshold space.

Hertzberger argues about the transition of space, using the term "threshold". He says that "The threshold provides the key to the transition and connection between areas with divergent territorial claims and, as a place in its own right, it constitutes, essentially, the special condition for the meeting and dialogue between areas of different orders" [8].

Threshold spaces consist of threshold combined with space elements. These elements could be one or more joint together. Together they create a unique spatial perception.

Threshold spaces preface main space or functional spaces, they can be outside the targeted space, mediate between two spaces and act as an in-between space as a breathing space, or an inside space. This is further illustrated in the case study of the historical city of Jeddah.

\subsection{Relevance of threshold to Islamic cities}

It is known historically that any city located within the boundaries of the Islamic country is considered a Muslim city, regardless of the type of the urban fabric. This structure usually emerges because of different factors such as the environmental, climate, economics, social and culture factors that differ from one region to another which helps in giving each city its distinctive character. To start it is important to look at city formation during the Islamic period to understand the organization of the threshold spaces.

When it comes to composition, Islamic cities went through different circumstances. Some cities were central like Baghdad where the government controlled the planning and buildings. Others were not central like the city of Mashhad in Iran as the city grew spontaneously. The Orientalist Van Grunebaum noted that the Islamic cities are divided to two different kinds. First, spontaneous cities which grew randomly. Second, created cities which were planned.

The style of the Islamic architecture is not linked by similarities but based on the shared customs and patterns of use which shows inner affinitions. There are certain denominators that are shared between them such as the climate condition and social factors. The social factors are based on the Islamic religion and peoples believe. And according to that, different design solutions were developed in different regions and cultures. As a result, from the above different setting were created with different solutions for designing the threshold space while sharing similar attributes that makes the Islamic cities different than other civilization when it comes to urban configuration and understanding of transitional spaces and its use.

It is argued that every city built during the Islamic era, had been fallowing the same principles of all other Islamic cities in terms of planning and design [9].

The architecture of the Islamic world had an exemplary response to the living conditions of the social and natural environment. Courtyards demonstrate a good example of the adaptation to the extreme climatic conditions of the occupied regions where cold winter 
nights and extreme hot days took place. The tight envelope with the protected interior shell "courtyard" gave an isolation and independency from the outer world, which served the social, religious, and environmental conditions. The feature of the enclosed courtyard became omnipresent in the Islamic architecture from the private house to the mosque. It is vital to remark that "the courtyard is a form of construction that have a presence since the humans started to build their houses" [10]. It is a common design feature particularly in houses used as a gathering space for house hold (Fig. 1).

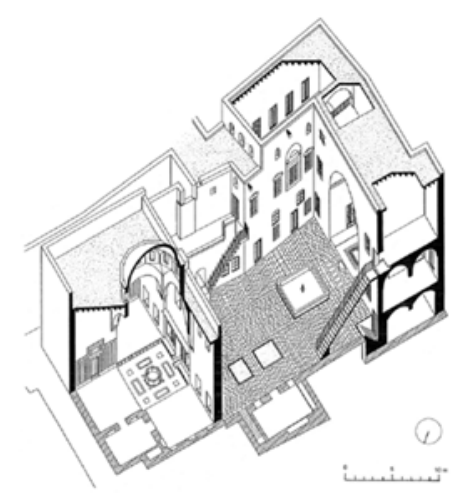

Figure 1: Aleppo showing the courtyard (on the left), a source of light, air and privacy [11, p. 116].

The structure of an Islamic city differs than other religions as it gave birth to a comprehensive and integrated cultural system by implanting religious practice in the life style of the individual and the society in general. According to that and in order to understand the urban and architectural structure it is important to tackle briefly the religious and social aspects of Islam.

The Islamic law "Sharia" was established around 200 years after the death of the prophet Mohammed. At that period Islam expanded beyond the Arabian Peninsula. With the huge empire and to meet the needs, the jurisprudence "Fiqh" was established that contributes to the development of the Islamic law "Sharia" and which is used to maintain the Islamic identity.

Hence, the special character and the urban layout was influenced by the practice of the Islam which also had an effect on the social structure and living habits of the Muslim people. As an example, The Hajj played a significant role not only on the commercial level but on the urban and architectural development of the city of Jeddah. There was a spread of yards which is a courtyard surrounded with a number of houses or rooms on two floors in the west side of the city "where the lower floors were used as storages for merchants' goods and the upper floors were rented by merchants, pilgrims and travels" [12] to spend the night in.

It is important to note that in the Islamic city the notion of sacred spaces refers not only to the mosque which is the religious building but also to homes which have a degree of sacredness to it. This is due to Islamic religion which is reflected in people believes and understanding of separation between both genders.

When looking at the urban configuration of the Islamic city, it is clear that it mostly follows an organic pattern of growth. It is made of different layers that take us from the public "mosque and surrounding market" gradually to the more private "residential district" by 
passing by a semi-public and a semi private layer. In other words, streets from the public area turns to private access corridors usually ending with col du sac. This is achieved by alleyways, and thresholds spaces. All this help in protecting the private sphere from the public.

Houses are either so close to each other or built wall to wall when the courtyard structure exists which creates the inward focus or core of the dwelling unit that is protected from the outer realm and used for social purposes.

In the Islamic city threshold spaces are used to define three spaces the inner courtyard, the space in front or around the building, and in some cases an internal space such as reception area "Dahliz". However, in Jeddah threshold spaces only defines two spaces the Dahliz and the space in front and around the building. These spaces had different applications in expressing the threshold. In order to understand the threshold space, it is important to analyse the streets to understand the organization and the relationship with its surroundings. "The study of the local context emphasises the importance of culture in the study of the street environment" [13].

Nooraddin [14] states, that different opinions concerning the definition of the boundaries of the transitional spaces and its regulations regarding private and public land were developed from Jurisprudence and these differences basically resulted in the particular method of Jurisprudence of each tradition. Furthermore, according to the literature, thresholds depends on identifying the application then the components. Four components were the results of each application as following:

1. Design;

2. Functions which includes use and the effect of the surrounding environment;

3. Type and behavior of people involved;

4. Organization order of the solution, function, and people involved.

Furthermore, some questions were considered by jurists in order to approve or disprove the application of the in between space some of the questions include the following:

1. The benefit either public or private;

2. Street width;

3. Cause and type of harm if applicable;

4. Alternatives in case of harm.

In the Islamic society the ownership of the threshold space was either private, public, or semi-public. This depends on the type of street and its location in the city which could be in the residential or commercial area as the right of benefit for the pedestrian and the neighbour is different. And according to Nooraddin as a consequence to the above some basic rights were developed to organize this space, such as the rights of passage, the right of sitting, the right of protect privacy, and the right of building.

\section{HISTORICAL JEDDAH AS A CASE STUDY}

Historical Jeddah "Al Balad" is located on the west coast of the Red Sea in the west province of Saudi Arabia "Hijaz region". It was the most famous Hijazi city and was a very important port in certain periods as it was located in the middle of the red sea close to other important ports. Moreover, it is the gate to Makkah during Hajj and other periods. All this played a role in the urbanization of the city as well as on the diverse culture we find till this day. In 1854 the Swiss traveller Didier wrote in his book "A trip to the Hijaz in the second half of the nineteenth century" that "most of Jeddah's population are from foreign origins" [15]. 
This diverse gave our western region the rich and distinct culture which makes it different than other parts of the country and at the same time creates this unique Hijazi culture that we have till this day. With no doubt the combination of different cultures affected many things such as the life style in general which includes social behaviours, believe, customs, urban configuration, and its architecture. My attempt in this part is to show the urban configuration of the historical city of Jeddah.

\subsection{The religion and the building environment}

As mentioned previously, religious, believes and customs "Urf" played an important role in shaping the Islamic cities including the old city of Jeddah as religion plays an important role in people lives.

Abu-Ghazzeh [16] noted that "Custom was particularly important among the early Muslim builders of Jeddah Al Qademah. In this Islamic society tradition had a clear religious meaning, and city residents shared a strong religious sense, convinced their way of life was an expression of the will of Islam".

The most important regulators for Muslims are Quran "the holy book" as well as Sunna "things said and done by the prophet" those two are the sources of law "Sharia" for all Muslims. According to Hakim [5, p. 137] “...the roots of the structure and unity prevalent in the numerus cities (within the fabric of each city) within the vast Islamic world are the product of the Figh: the mechanism interpreting and applying the value system of the Sharia (Islamic Divine Law) within the processes of building and urban development".

After a brief explanation of the role of Islamic believes and Urf "customs" on the built environment, we can continue by exploring the urban morphology and threshold spaces of the old city of Jeddah according to the Islamic principles and to do so, it is essential to study the plan organization.

In the early development of the city we can observe two things, first, the circular shape of the city which also included several conceptual planning such as: the fortification, external fence, water storage system, straight streets, as well as fortification through digging trenches for military purposes which was the influence of the Persians since they ruled the trading in the Hijaz. Second, the movement in the city through the roads that connected the core and main streets with the residential area. Moreover, the development that took place later was based on Sharia law which gave the city the character we see today.

\subsection{The wall and the market "souk"}

Many travels described the wall, gates, and fortification towers of Jeddah after their visit. The wall was built and demolished several times. In general, we can say that the wall did not fallow a geometrical shape. This is due to the topography in the area and because parts of the urban fabric which was established prior to the construction of the wall. The ancient gates of the city include Bab Medina to the North, Bab Makkah to the East, Bab Sharif to the South. Moreover, there were many other gates that don't exist anymore such as Bab Al Bant located on the West side of the city where the Pilgrims and Merchandises would enter the city of Jeddah.

Jeddah is known for its strategical location which makes it an important commercial hub. Furthermore, it's a gate to Makkah bringing people and merchants from all over the world with infinite verity of goods which led to the emergence of many markets "souk". These markets played an important role in the development of the old city of Jeddah. Moreover, they took many forms for goods exchange and were located in different areas within the city 
wall. First, A central market constructed of one story and made of many shops were located in an open area in the south area of the great mosque. Second, markets were also located along thoroughfares between the core and the city gates. Third, open space markets located on both sides of the city walls and its gates. Fourth, seasonal/weekly markets located in public areas on major thoroughfares of the city. Lastly, mini markets, grocery stores, and small mosques were located in neighbourhood as centres or focal points all around the city (Fig. 2).
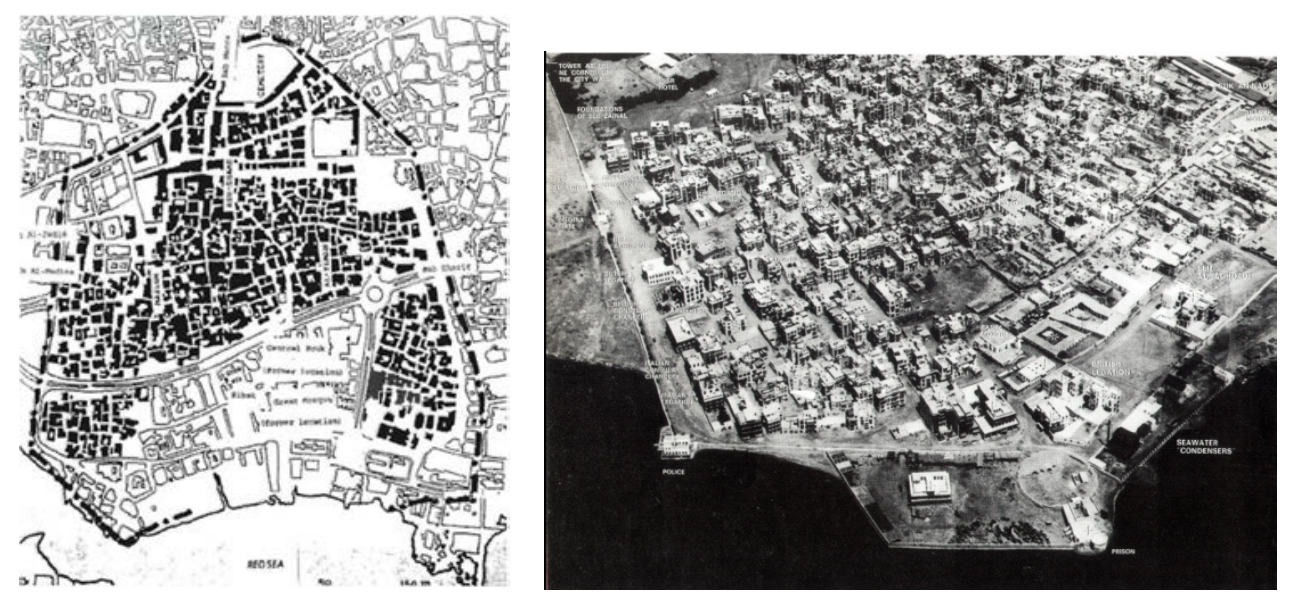

Figure 2: Layout of Old Jeddah showing the wall, the cluster organization, major east west roads which cut through. (Source: Left: [16, p. 52], Right: [17, p. 112].)

\subsection{Streets and neighbourhoods}

Streets were constructed according to the movement requirements. Just as other Islamic cities these streets were developed for pedestrian traffic as well as animals. Street width was determined through the movement of two loaded animals to pass. Again, just like other Islamic cities streets displayed a clear hierarchy from public to semi-public to private which we can consider as a tripartite system.

- The wide thoroughfares from the city gates to the core.

- Primary streets between the major quarters of the city connecting residential areas with the city center.

- Third order streets provide link between quarters and is mainly used by people who live and work in the area.

- $\quad$ Cul de sacs, these are not public and belong to adjacent buildings. In Islamic cities cul de sacs are used for privacy and isolation purposes unlike in roman or medieval cities.

The old city of Jeddah was made of four quarters "Harat" these are; Harat al Mazloum to the north-eastern part. Harat al Sham located in the North part. Harat al Bahar is located in the south-western part of Jeddah overlooking the Red Sea. Harat al Yaman to the South part of the old City of Jeddah. Each quarter is made of subsections. Each subsection has all the requirements for social life such as a local mosque, scholarly activities, and mini markets. In these residential areas streets between dwellings are called "Darb or Zugag" and these are 
usually covered by projected bay windows that shier view and is made of wood "Roshan" these are used for women privacy (Fig. 3).

Heights of buildings were determined according to neighbour's respect as well as access to breeze. Usually they were three to six stories height clustered around and enclosed social spatial domain called "Baraha".
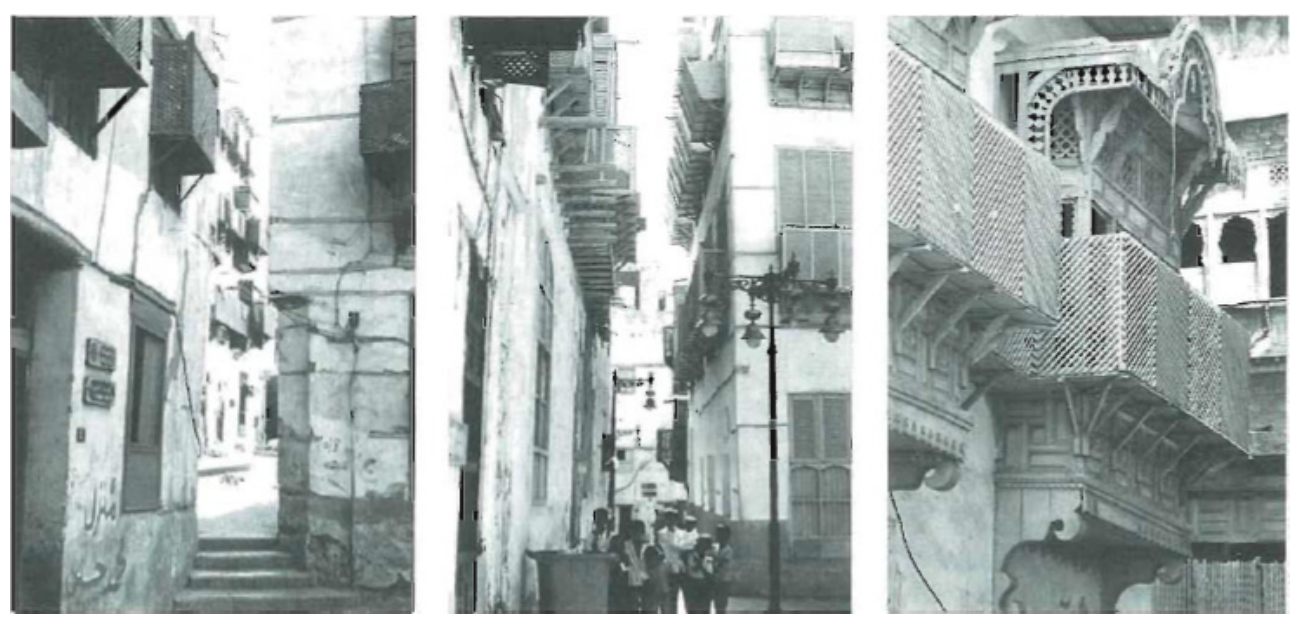

Figure 3: Left and centre, narrow third order streets linking spaces within quarters. Right, projected balconies that shier view and is made of wood "Roshan" these are used for women privacy [18, p. 55].

\section{ALEXANDER'S THEORY AND ITS IMPACT ON SOCIAL AND SPATIAL LEVEL IN JEDDAH}

According to my field work in the historical city of Jeddah a number of patterns were identified on different scales (time, body, building, street, and city). Some of these patterns were mentioned in Christopher alexander book "A Pattern Language" using the same heading or names in the book or having a different heading according to the local name used in the Hijaz region. Moreover, new patters were identified specifically related to the city of Jeddah and other coastal cities on the rim of the Red Sea.

In this paper I will explain one pattern out of eighteen patterns found in the old city of Jeddah. This pattern is identified in "A Pattern Language" by Christopher Alexander and his team. The pattern is "Street windows" named locally Roshan. This pattern falls under the building scale and is one of the important architectural features in the historical city of Jeddah. Moreover, the eighteen patterns were divided to three different categories: male, female, and both. This classification depends on its use. Male patterns describe patterns that are used mainly by men. Female patterns define patterns that are used mainly by women. Both refers to patterns that are used by both genders.

\section{STREET WINDOWS "ROSHAN"}

Windows help us in viewing the outside world offering an engagement with the street or square through the exchange of smells and sounds.

"A street without windows is blind and frightening. And it is equally uncomfortable to be in a house which bounds a public street with no window at all on the street" [3, p. 770]. 


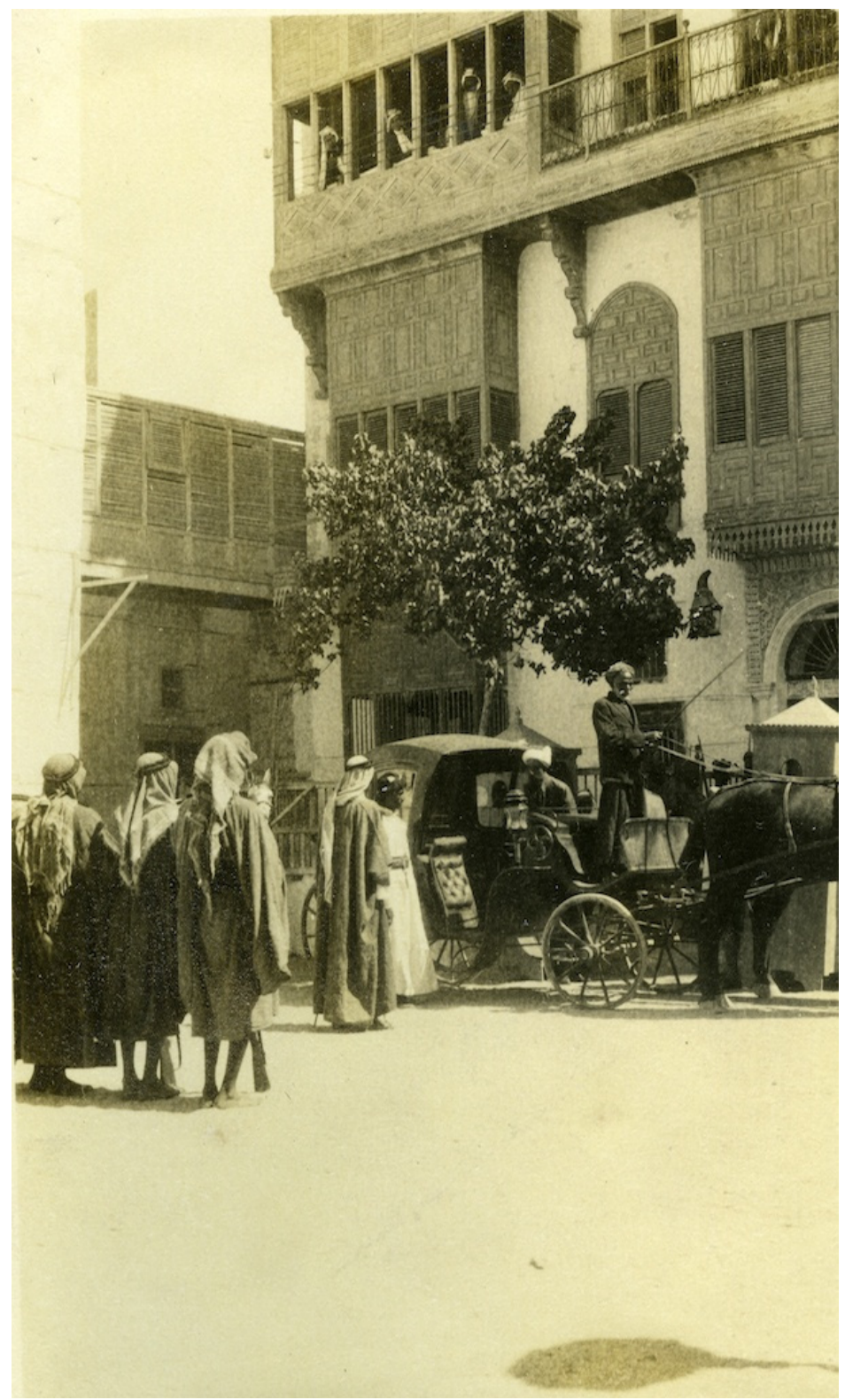

Figure 4: Al Sharif Taha Mhana House taken by St John Philby 1925. (Source: http://lostopportunitiesandwastedtimes.blogspot.com/2014/07/blogpost_25.html.)

Street windows are threshold patterns which gives a unique experience by connecting the life inside of the house to the outside world. In the old city of Jeddah Street windows Locally termed "Roshan" are bay windows and are one of the distinguishing external features of its houses. It was admired by many travellers and explorers who visited the city. 
This female pattern varies in size and taste as it reflects the wealth of the owner of the house because it's the most expensive part of the house. Its main use is for air ventilation as the air enters from three different areas, light penetration without direct sun light, and privacy for women as they can sit in it to look at the outer world without being seen by strangers from the outside "Roshan acted as an intermediary zone offered an excellent solution to the problem of both the social and climatic interaction" [18].

According to Abudoad [19], it was the most important sitting area in the old houses of Jeddah many social activities took place there. "They were used for various social activities, including chatting, sipping tea or coffee, smoking shishah, watching the world go by down in the streets as well as sleeping" [20].

According to an interview with Badeeb I was told that Women who lives in houses with large street window "Roshan" that don't look at large streets may communicate through these windows if the distance is not much (Fig. 5).

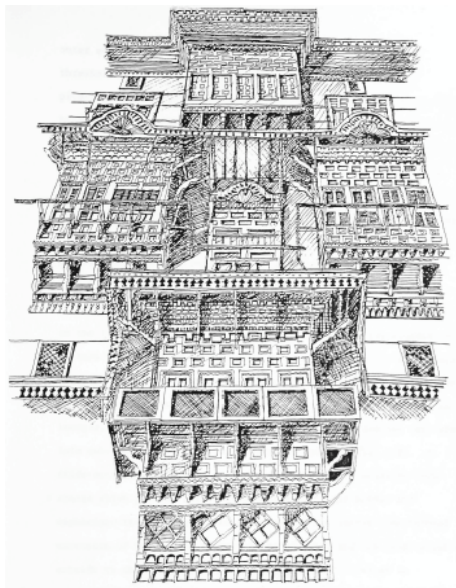

(a)

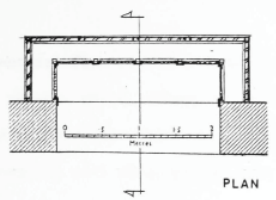

(b)

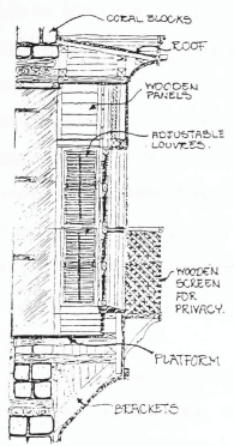

(c)

Figure 5: (a) Decorative street window "Roshan" in one of the houses in Jeddah [21, p. 69]; and (b) and (c) Showing the detail of a street window "Roshan" in old Jeddah [21, p. 249].

Street windows in old Jeddah was located on all floors and sometimes on all four façades with more attention given the main façade. "The number of street windows varies in each house according the location of the façade. Façades that looks at the main street or open spaces 'Barhat' had the greatest number of windows because of ventilation and to have a large angle of view" [22, p. 250]. Moreover, the number of windows differ from one house to another depending on the size of the façade and the number of floors. Roshan size and hight differs according to the available interior spaces. When the room is large it requires from the architect larger street windows and vice versa. In addition, the back façades did not take the same importance of the main façade when it comes to arranging the Street Windows "Roshan" as they were located randomly with no care about their relationship to each other, its main purpose was to serve the ventilation of the room [22, p. 251].

Alexander et al. [3, p. 771] states that street windows are most successful on the second and third floors. Anything higher, and the street becomes a "view" - the vitality of the connection is destroyed. At ground level street windows are less likely to work. If they are 
too far back from the street, they don't really give a view onto the street, though of course they still give height.

Therefore, "Where buildings run alongside busy streets, build windows with window seats, looking out onto the street. Place them in bedrooms or at some point on a passage or stair, where people keep passing by. On the first floor, keep these windows high enough to be private" [3, p. 771] (Fig. 6).

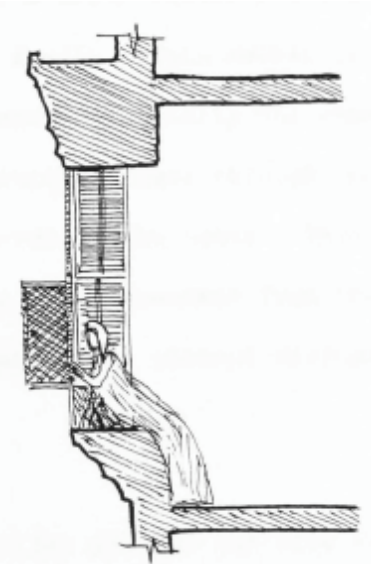

(a)

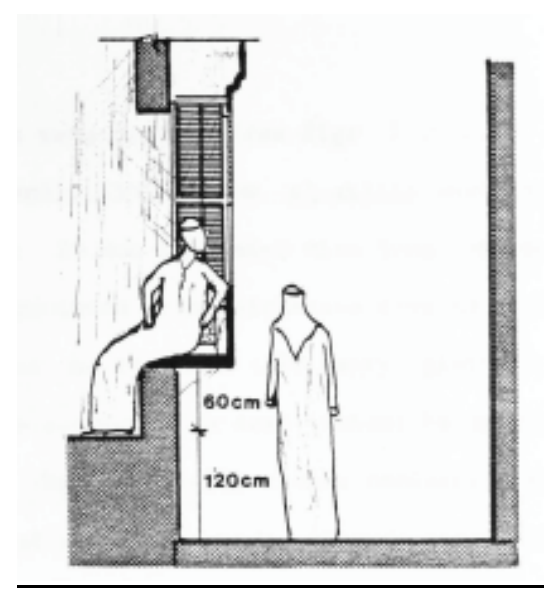

(b)

Figure 6: (a) Street windows allow women to see the outer world without being seen [23, p. 76]; and (b) Street windows should not be located on the ground level but a bit elevated from the ground floor [24, p. 199].

Giving each window its special character such as Window places makes it more likely to be used from the inhabitants on the other hand, decorating the Street windows "Roshan" from the outside and give it bright colours makes it interesting for people in the street to look at.

\section{CONCLUSION}

The paper looked at the theory of Christopher Alexander and his team with an emphasis on threshold spaces to explore patterns between public and residential units which played an important role in assisting the public life in Old Jeddah. Many factors such as religion, climate, believes and customs affected the urban configuration of Islamic cities including Jeddah and as a result affected the architecture typology of the threshold spaces.

Eighteen patterns were identified in Al Balad, some are the same version of patterns found in "A Pattern Language" and others are totally different as they fit to the context of Jeddah and other cities on the rim of the Red Sea. This indicates that the findings of A pattern Language by Alexander and his team are not only specified to a certain context, it can be used by different cultures to explore old cities and find new patterns that are exclusive to certain cultures.

\section{REFERENCES}

[1] Madanipour, A., Public and Private Spaces of the City, Routledge: London, 2003.

[2] Zoller, D., Herausforderung Erdgeschoss = Ground Floor Interface, Jovis: Berlin, p. 33, 2014. 
[3] Alexander, C., Ishikawa, S., Silverstein, M., Jacobson, M., Fiksdahl-King, I. \& Angel, S., A Pattern Language, Oxford University Press: New York, 1987.

[4] UNESCO World Heritage Centre, Historic Jeddah, The Gate to Makkah. http://whc.unesco.org/en/list/1361. Accessed on: 27 Oct. 2017.

[5] Hakim, B.S., The URF and its role in diversifying the architecture of traditional Islamic cities. Journal of Architectural and Planning Research, 11(2), pp. 112, 137, 1994.

[6] Van Gennep, A., The Rites of Passage, translated by Monika Vizedom and Gabrielle L. Caffee, University of Chicago Press: Chicago, p. 18, 1960.

[7] Turner, V.W., Secular Ritual, Van Gorcum: Assen, 1977.

[8] Hertzberger, H., Lessons for Students in Architecture, translated by Ina Rike, 010 publishers: Rotterdam, p. 32, 2005.

[9] Gargaja, F., Aspects of the structure of Arabic Islamic city. Researches of Essential College Journal, pp. 1-11, 2011.

[10] Bridson, D., Courtyard Housing Study-Djingis Khan and The Kingo Houses, p. 1, 2012.

[11] Ragette, F., Traditional Domestic Architecture of the Arab Region, Edition Axel Menges, 2003.

[12] Maghrabi, M., Al Imara Al Islamia. Majalt Iqraa, Special Edition, p. 34, 1981.

[13] Rapoport, A., History and Precedent in Environmental Design, Plenum Press: New York, 1990.

[14] Nooraddin, H., Al-Fina, in-between spaces as an urban design concept: Making public and private places along streets in Islamic cities of the Middle East. Urban Design International, 3(1-2), p. 68, 1998.

[15] Didier, C., A Trip to the Hijaz in the Second Half of the Nineteenth Century, translated by Mohammed Albakai, Dar al Faisal Althakafia, p. 184, 1854.

[16] Abu-Ghazzeh, T.M., Built form and religion: Underlying structure of Jeddah AlQademah. Traditional Dwellings and Settlements Review, 5(2), p. 50, 1994.

[17] Pesce, A., Jiddah: Portrait of an Arabian City, Falcon Press, 1977.

[18] Eyuce, A., Comparative analysis of solid-void relationships of traditional and contemporary houses in the western region of Saudi Arabia. Scientific Research Administration of College of Engineering KAAU, p. 38, 1985.

[19] Abudoad, A., Jeddah and the Jedawion. Mansour Al Zamil Publishing and Distribution House, p. 460, 2017.

[20] Khan, S. \& Goodfellow, R., Jeddah Old Houses: A Study of Vernacular Architecture of the Old City of Jeddah, p. 13, 1981.

[21] Talib , K., Shelter in Saudi Arabia, Academy Editions: London, 1984.

[22] Al Thakafi, A., Al Omara fi Madinat Jeddah fi Alasr Al Othmani. PhD thesis, p. 250, 2010.

[23] Al-Lyaly, S.M.Z., The Traditional House of Jeddah: A Study of the Interaction between Climate, Form and Living Patterns, University of Edinburgh, 1990.

[24] Kurdi, T.M., Influence of Arabian tradition on the old city of Jeddah: House form and culture. The Arab City: Its Character and Islamic Culture Heritage, eds I. Serageldin \& S. el-Sadek, Riyadh, 1981. 